Personality: A source of test bias?

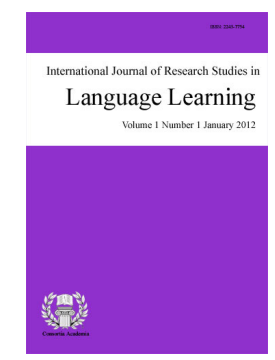

ISSN: 2243-7754 Online ISSN: 2243-7762

OPEN ACCESS

Ajideh, Parviz

University of Tabriz,Iran (Parvizaj@gmail.com)

Yaghoubi-Notash, Massoud

University of Tabriz, Iran (Masoud.yaghoubi@gmail.com)

Khalili, Abdolreza $\triangle$

University of Tabriz, Iran (Abdolrezaa.khalili@gmail.com)

\title{
Abstract
}

The present study investigated the relationship between the EFL learners' personality traits and their performance on the English vocabulary and grammar tests. Based on this aim, first, 158 intermediate EFL learners were selected from among 324 language learners of a private language institute in Urmia (Iran) as the participants of the study based on their results on a proficiency test. Second, the participants respectively received the NEO-Five-Factor Inventory (Costa \& McCrae, 1992), the vocabulary test of the study, and the grammar test of the study for the determination of their personality traits, English vocabulary test performance, and English grammar test performance during three sessions in a 10-day period. The standard multiple regression was employed for data analysis. The results of the study showed that, the learners' openness to experience and extraversion personality traits had significant positive correlations with their vocabulary and grammar test performance and these traits significantly contributed to the prediction of the variance in the results of these tests. It was argued that, personality may be regarded as a source of bias in second language test performance. The results of the study may provide practical guidelines for the EFL teachers and syllabus designers. Moreover, these results may have theoretical implications for second language testing specialists in the process of test validation.

Keywords: individual learner differences; personality; personality traits; test bias; test validation 


\section{Personality: A source of test bias?}

\section{Introduction}

The study of individual learner differences has a long history and these differences have been among the extensively investigated areas in language teaching (Ellis, 2008). The learner differences include the "enduring personal characteristics that are assumed to apply to everybody and on which people differ by degree" (Dörnyei, 2005, p. 4). As Ellis (2008) noted, the early studies of these individual differences, which were conducted before the beginning of the field of Second Language Acquisition (SLA), focused on designing specific testing instruments such as the Modern Language Aptitude Battery (Carrol \& Sapon, 1959) and tried to determine the individuals who had a high level of language aptitude and were likely to be successful in learning a second or foreign language. According to Horwitz (2000, p. 527), as a result of these early studies, language learners were called "good and bad, intelligent and dull, motivated and unmotivated". However, as Segalowitz (1997) argued, the more recent studies of the learner differences have tried to determine why some of the learners are more successful in comparison with the others. According to him, these studies can be considered to be complementary to the mainstream research in SLA. As Horwitz (2000, p. 532) noted, as a result of these studies the language learners were called "integratively and instrumentally motivated, anxious and comfortable, field independent and field sensitive, auditory and visual".

As Skehan (1989) argued, a large number of the individual learner difference studies have tried to determine the correlations between certain individual differences such as intelligence and achievement in second language learning. However, as Bachman (1990) stated, these differences can be regarded as sources of test bias. According to him, the learners' scores on different language tests may be influenced by four categories of factors including: communicative language ability, test method facets, personal attributes, and random factors. As he noted, while the random factors are "largely unpredictable and temporary" (p. 164), the test method facets and personal attributes affect the test takers' test performance regularly. As he explained:

\section{Random factors and test method facets are generally considered to be sources of measurement error, and have thus been the primary concern of approaches to estimating reliability. Personal attributes that are not considered part of the ability tested, such as sex, ethnic background, cognitive style, and prior knowledge of content area, on the other hand, have traditionally been discussed as sources of test bias or test invalidity (p. 166).}

According to Farhady (1982), the studies of test bias are essential in the process of test validation since their results may lead to the redefinition of the construct of language ability. Moreover, as Bachman (1990) argued, these studies "raise questions about the extent to which language abilities as constructs are independent of the content and context of the language use elicited in their measurement" (p. 279). As he concluded, the test bias studies may provide a better understanding of the measurement value of language tests, the characteristics of successful language learners, and the role of individual learner differences in the process of test validation.

A review of the related literature (e.g. De Raad, 2000; Ehrman \& Oxford, 1995; Goldberg, 1992; McCrae \& Costa, 2003; Myers \& Briggs, 1976) shows that among the individual learner differences, personality has been investigated by a number of SLA researchers. Personality involves "those aspects of an individual's behavior, attitudes, beliefs, thought, actions, and feelings which are seen as typical and distinctive of that person and recognized as such by that person and others" (Richards \& Schmidt, 2010, p. 431). It represents those characteristics of a person that "account for consistent patterns of feeling, thinking, and behaving" (Pervin \& John, 2001, p. 4).

According to Pervin and John (2001), personality has been investigated within numerous theoretical frameworks and a large number of personality factors have been proposed based on these paradigms. However, 
as they noted, among the different models of personality, Eysenck's Three-Component Model (e.g. Eysenck \& Eysenck, 1985), and the Big Five Model of Personality (e.g. Goldberg, 1992) have been employed by the SLA researchers. According to Dörnyei (2005), the revised version of Eysenck's personality model (e.g. Eysenck \& Eysenck, 1985) identifies three principal personality dimensions "contrasting 1) extraversion with introversion, 2) neuroticism and emotionality with emotional stability, and 3) psychoticism and toughmindedness with tender-mindedness" (p. 13). Moreover, as he noted, an examination of the Big Five Model of Personality shows that, it somehow overlaps with Eysenck's Three-Component Model since it maintains the first two components of the previous model (i.e. extraversion /introversion \& neuroticism / emotional stability). However, the last component (i.e. psychoticism) is exchanged with three other factors including: conscientiousness, agreeableness, and openness to experience. According to him, the Big Five Model of Personality has been very influential in personality research since it involves "a fairly straightforward and parsimonious system that still captures a considerable proportion of the variance" (p. 14).

Dörnyei (2005) defined each of the dimensions of the Five Factor model. His definitions are provided below:

> Openness to experience: High scorers are imaginative, curious, flexible, creative, moved by art, novelty seeking, original, and untraditional; low scorers are conservative, conventional, down-to-earth, inartistic, and practical.

> Conscientiousness: High scorers are systematic, meticulous, efficient, organized, reliable, responsible, hard-working, persevering, and self-disciplined; low scorers are unreliable, aimless, careless, disorganized, late, lazy, negligent, and weak-willed.

D Extraversion-introversion: High scorers are sociable, gregarious, active, assertive, passionate, and talkative; low scorers are passive, quiet, reserved, withdrawn, sober, aloof, and restrained.

> Agreeableness: High scorers are friendly, good-natured, likeable, kind, forgiving, trusting, cooperative, modest, and generous; low scorers are cold, cynical, rude, unpleasant, critical, antagonistic, suspicious, vengeful, irritable, and uncooperative.

$>$ Neuroticism-Emotional stability: High scorers are worrying, anxious, insecure, depressed, self-conscious, moody, emotional, and unstable; low scorers are calm, relaxed, unemotional, hardy, comfortable, content, even tempered, and self-satisfied (p. 15).

However, a close examination of the relevant literature shows that, most of the empirical studies of personality have focused on its extroversion/introversion dimension (e.g. Busch, 1982; Mall-Amiri \& Nakhaie, 2013; Strong, 1983) and have not dealt with its other dimensions. Moreover, the majority of these studies have tried to determine the relationship between personality and language achievement (e.g. Dewaele \& Furnham, 2000) and have ignored the role of personality as a bias factor in language tests. Finally, the few studies which have dealt with the mentioned issues (e.g. Verhoeven \&Vermeer, 2002) have been conducted in second language contexts and there is not sufficient information regarding personality in foreign language contexts. In the English as a Foreign Language (EFL) context of Iran, the same gaps are apparent in the related literature of personality. More specifically, there is a lack of research regarding the role of personality as a bias factor in different tests of the second language including the vocabulary and grammar tests.

The present study tried to deal with the mentioned gaps of the literature regarding the personality. Based on this aim, it examined the EFL learners' personality traits as bias factors in their English vocabulary and grammar test performance. That is, the study tried to answer the following research questions:

$>$ Is there any relationship between the EFL students' personality traits and their vocabulary test performance? 
Ajideh, P., Yaghoubi-Notash, M., \& Khalili, A.

$>$ Is there any relationship between the EFL students' personality traits and their grammar test performance?

\section{Materials and Methods}

\subsection{Design of the Study}

According to Creswell (2011), the correlational design is one of the main research designs in the quantitative approach to research. As he explained, this design involves two main types including the explanatory design and the prediction design. In discussing the different aspects of the prediction design he argued that:

The purpose of the prediction design is to identify variables that will predict an outcome or criterion. In this form of research the researcher identifies one or more predictor variables and a criterion or outcome variable. A predictor variable is a variable which is used to make a forecast about an outcome in correlational research....The outcome being predicted in correlational research, however, is called the criterion variable (p. 341).

An examination of the purpose, data collection, and data analysis of the present study shows that, it employed a quantitative approach and was conducted based on a predictive correlational design in which the personality traits were the predictor variables and the learners' performances on the vocabulary and grammar tests were the criterion variables.

\subsection{Participants}

In the present study, 158 intermediate EFL learners were selected from among 324 language learners of a private language institute in Urmia (Iran) as the participants of the study based on their results on the Objective Placement Test (Lesley, Hansen, \& Zukowski, 2003). The selected participants: were male, raged in age from 15 to 26 , and had 2 to 3 years of language studies in the language institute. They were from Urmia and were native speakers of Azeri. In order to select these participants, first, the researchers determined the mean value of the 324 language learners' results on the proficiency test of the study. Second, they selected the learners whose score were within 1 Standard Deviation (SD) below and above the mean value of the group.

\subsection{The Instruments and Materials of the Study}

The following instruments and materials were employed in the present study:

Proficiency Test - The present study tried to determine the relationship between the intermediate EFL learners' personality traits and their test performance. Based on this aim, the Objective Placement Test, from New Interchange Passages Placement and Evaluation Package (Lesley, Hansen, \& Zukowski, 2003) was employed in order to select the participants of the study. This test consisted of four parts: Listening, Grammar, Vocabulary, and Reading. The Listening section involved 20 recorded items. The Grammar section had 30 items. The Vocabulary section consisted of 30 items and the Reading section had 20 items.

The NEO-Five-Factor Inventory - In order to determine the selected participants' personality traits, Costa and McCrae's (1992) NEO-Five-Factor Inventory was employed in the present study. This self-report questionnaire includes 60 items that examine the five main personality domains of the BIG FIVE model of personality (e.g. Goldberg, 1992) including: Neuroticism, Extraversion, Openness to Experience, Agreeableness, and Conscientiousness. As Costa and McCrae (1992) stated, each of these domains involves six lower-level facets: Neuroticism (Anxiety, Angry Hostility Depression; Self-Consciousness, Impulsiveness, \& Vulnerability); Extraversion (Warmth, Gregariousness, Assertiveness, Activity, Excitement-Seeking, \& Positive Emotions); Openness to Experience (Fantasy, Aesthetics, Feelings, Actions, Ideas, \& Values); Agreeableness (Trust, Straightforwardness, Altruism, Compliance, Modesty, \& Tender-Mindedness); and Conscientiousness 
(Competence, Order, Dutifulnes, Achievement Striving, Self-Discipline, \& Deliberation). According to them, each of these facets is represented by two items of the questionnaire and therefore each personality domain is represented by 12 items.

As Costa and McCrae (1992) argued, the participants answer the items of this questionnaire on a 5-point Likert scale (i.e. $1=$ strongly disagree; $2=$ disagree; $3=$ neutral; $4=$ agree; $5=$ strongly agree) and the higher scores in each domain show more characteristics of the relevant personality domain. Moreover, as they noted, the reliability index of this questionnaires is .86 and its validity has been guaranteed by factor analysis.

The Vocabulary Test of the Study - Based on the aims of the present study, a 40-item researcher-made multiple-choice vocabulary test was employed in order to determine the participants' vocabulary test performance. The items of this test were developed based on the vocabulary items of the reading texts of Intermediate Select Readings (Lee \& Gundersen, 2011).

In order to guarantee that the test was a reliable and valid instrument for measuring the participants' vocabulary knowledge, it was piloted with 75 male ELF learners which had similar characteristics to the participants of the study. Since the items of the test were based on the reading texts that were specifically developed for the intermediate-level language learners, their content validity was guaranteed. However, in order to determine the empirical (concurrent) validity of the test, the results of the selected 75 learners on this test were correlated with their results on the vocabulary section of the Objective Placement Test (Lesley, Hansen, \& Zukowski 2003). The results of the analysis showed that, the empirical validity index of the test was .82 which, as Harris (1969) stated, is regarded to be satisfactory for researcher/teacher-made tests. Moreover, a test-retest method was employed in order to determine the reliability of the test. Based on this aim, the selected $75 \mathrm{EFL}$ learners took this test twice during a one month period and their results on the two sessions were correlated. The results of this analysis showed that, the reliability index of the vocabulary test was .87 which, as Harris (1969) stated, is regarded to be satisfactory for researcher/teacher-made tests.

The Grammar Test of the Study - In order to determine the selected participants' grammar test performance, a 40-item researcher-made multiple-choice grammar test was employed in the present study. Similar to the vocabulary test, the items of this test were based on the reading texts of Intermediate Select Readings (Lee \& Gundersen, 2011). That is, the researchers extracted the grammar points of these reading texts and developed the test items based on these points. In order to guarantee the reliability and validity of this test, the researchers piloted it with 75 male EFL learners with similar characteristics to selected participants. Since the test items were based on intermediate-level reading texts (i.e. texts of Intermediate Select Readings) their content validity was guaranteed. However, in order to determine the empirical (concurrent) validity of the test, the results of the selected 75 learners on this test were correlated with their results on the grammar section of the Objective Placement Test (Lesley, Hansen, \& Zukowski, 2003). The results of the analysis showed that, the empirical validity index of the test was .78 which, as Harris (1969) stated, is regarded to be satisfactory for researcher/teacher-made tests. Moreover, a test-retest method was employed for determining the reliability of the test items. That is, the selected learners took the test twice during a one month period and their results were correlated. Based on the results, the reliability index of the grammar test was .84 which, as Harris (1969) stated, is regarded to be satisfactory for researcher/teacher-made tests.

\subsection{The Procedure of the Study}

In this study, first, 158 intermediate EFL learners were selected from among 324 language learners of a private language institute in Urmia (Iran) as the participants of the study based on their results on the Objective Placement Test (Lesley, Hansen, \& Zukowski, 2003). Second, the participants received the NEO-Five-Factor Inventory (Costa \& McCrae, 1992) for the determination of their personality traits. The administration of this questionnaire took about 30 minutes. Third, the vocabulary test of the study was administered to the participants for the assessment of their English vocabulary test performance. This test took about 45 minutes of the class time. 
Ajideh, P., Yaghoubi-Notash, M., \& Khalili, A.

Finally, the participants received the grammar test of the study for the examination of their English grammar test performance. It took the participants about 45 minutes to answer the items of this test. The questionnaire and the tests of the study were administered to the participants during three sessions in a 10-day period. The Statistical Package for the Social Sciences (SPSS) Version 20 was employed for the data analysis of the study.

\section{Results}

The first research question of the study tried to determine the relationship between the EFL students' personality traits and their vocabulary test performance. Based on the aims of this research question, a Standard Multiple Regression test was run between the participants' results on the personality inventory and their performance on the vocabulary test. In the regression analysis, first, the assumption of multicoliniarity had to be checked. In order to check this assumption, the collinearity diagnostics including Tolerance and Variance Inflation Factor (VIF) were determined. According to Pallant (2007):

Tolerance is an indicator of how much of the variability of the specified independent is not explained by the other independent variables in the model. If this value is very small (less than .10), it indicates that the multiple correlation with other variables is high, suggesting the possibility of multicollinearity. The other value given is the VIP, which is just the inverse of the Tolerance value (1 divided by Tolerance). VIF values above 10 would be a concern, indicating multicollinearity (p. 156).

The Tolerance and VIF values of the regression model for the vocabulary test are provided in Table 1 below:

\section{Table 1}

The Collinearity Diagnostics of the Learners' Personality Traits and Vocabulary Test Performance

\begin{tabular}{lcc}
\hline \multicolumn{1}{c}{ Model } & Tolerance & VIF \\
\hline Neuroticism & .745 & 1.341 \\
Extraversion & .901 & 1.109 \\
Openness to Experience & .876 & 1.142 \\
Agreeableness & .827 & 1.210 \\
Conscientiousness & .739 & 1.353 \\
\hline
\end{tabular}

As Table 1 shows, all of the Tolerance values of the model were more than .10, and all of the VIF values were less than 10 . Therefore, the multicollinearity assumption was not violated. Moreover, in order to determine the outliers, the Mahalanobis distance value was checked. As Pallant (2007) noted, for a model with 5 independent variables this value should not exceed "20.52" (p. 157). The results of residuals statistics for this model are provided in Table 2 below:

Table 2

Regression Model of the Learners' Personality Traits and Vocabulary Test Performance

\begin{tabular}{lccccc}
\hline & Minimum & Maximum & Mean & Std. Deviation & $\mathrm{N}$ \\
\hline Mahal. Distance & 1.093 & 11.474 & 4.968 & 2.218 & 158 \\
Cook's Distance & .000 & .080 & .008 & .017 & 158 \\
\hline
\end{tabular}

According to Table 2, the maximum value of the Mahalanobis distance (11.474) was less than 20.52 and therefore this assumption was not violated. Finally, in order to check the remaining assumptions the maximum value of the Cook's distance was checked. According to Pallant (2007), this value should be less than 1. As Table 2 shows, this value (.080) was less than 1 and therefore none of the assumptions was violated. Since all of the assumptions of the Multiple Regression were present, the regression model of the learners' personality traits and vocabulary test performance was evaluated. Table 3 below provides the summary of this model: 
Table 3

The Regression Model Summary of the Learners' Personality Traits and Vocabulary Test Performance

\begin{tabular}{ccccc}
\hline Model & $\mathrm{R}$ & $\mathrm{R}$ Square & Adjusted R Square & Std. Error of the Estimate \\
\hline 1 & .427 & .182 & .155 & 7.776 \\
\hline
\end{tabular}

According to Table 3, this model explains 0.182 (i.e. $R$ Square value) of the variance of the learners' performance on the vocabulary test. That is, this model explains 18.2 percent (R Square value multiplied by 100, by shifting the decimal point two places to the right) of the variance in the vocabulary test performance. However, in order to check the statistical significance of the predictive power of the model the results of the ANOVA test of the model had to be checked. The results of this test are provided in Table 4 below:

\section{Table 4}

The ANOVA Test of the Regression Model of the Learners' Personality Traits and Vocabulary Test Performance

\begin{tabular}{lccccc}
\hline \multicolumn{1}{c}{ Model } & Sum of Squares & df & Mean Square & F & Sig. \\
\hline Regression & 2049.297 & 5 & 409.859 & 6.779 & .000 \\
Residual & 9190.576 & 152 & 60.464 & & \\
Total & 11239.873 & 157 & & & \\
\hline
\end{tabular}

As Table 4 shows, the predictive power of the model was not equal to 0 since the p-value of the ANOVA test .000 (marked as Sig.) was less than the level of significance .05. Finally, in order to determine the contribution of each of the independent variables to the prediction of the variance of the vocabulary test results the Standardized Coefficients had to be checked. These results are provided in Table 5 below:

Table 5

The Coefficients of the Regression Model of the Learners' Personality Traits and Vocabulary Test Performance

\begin{tabular}{|c|c|c|c|c|c|}
\hline \multirow[t]{2}{*}{ Model } & \multicolumn{2}{|c|}{ Unstandardized Coefficients } & \multirow{2}{*}{$\begin{array}{c}\text { Standardized } \\
\text { Coefficients } \\
\text { Beta } \\
\end{array}$} & \multirow[t]{2}{*}{$\mathrm{t}$} & \multirow[t]{2}{*}{ Sig. } \\
\hline & $\mathrm{B}$ & Std. Error & & & \\
\hline (Constant) & 11.058 & 3.884 & & 2.847 & .005 \\
\hline Neuroticism & .029 & .050 & .048 & .570 & .569 \\
\hline Extraversion & .112 & .042 & .209 & 2.705 & .008 \\
\hline $\begin{array}{l}\text { Openness to } \\
\text { Experience }\end{array}$ & .284 & .054 & .413 & 5.273 & .000 \\
\hline Agreeableness & .033 & .049 & .053 & .661 & .510 \\
\hline Conscientiousness & -.082 & .056 & -.126 & -1.482 & .140 \\
\hline
\end{tabular}

According to Table 5, the largest Beta value is .413 which is for the Openness to Experience variable. Therefore, it can be argued that, this variable makes the strongest unique contribution to explaining the results of the vocabulary test when the variance explained by all of the other variables in the model is controlled. Moreover, since the p-value for this variable .000 (marked as Sig.) was less than the level of significance .05 , it was argued that this variable made a statistically significant unique contribution to the prediction of the vocabulary test results. Furthermore, based on the results, Extraversion (Beta=.209, Sig=.008) was the second variable that made a significant contribution to the results of this test. The significant contributions of these variables to the explanation of the results of this test are respectively depicted in Figure 1 and Figure 2 below:

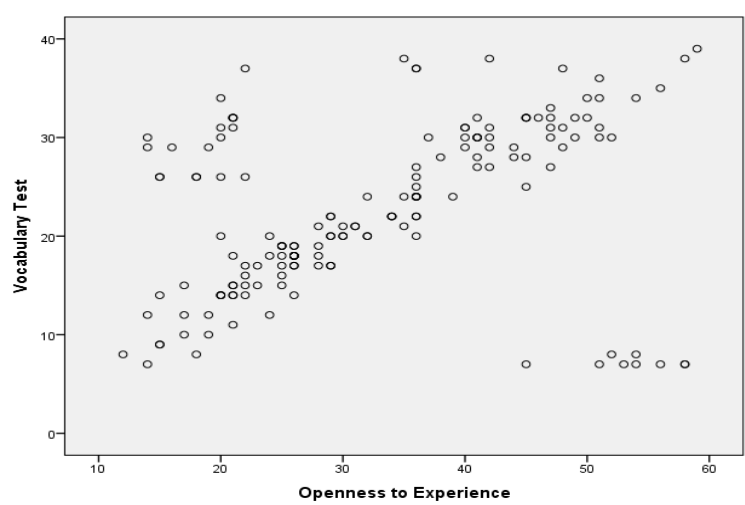

Figure 1. Correlation between the openness to experience personality trait and vocabulary test performance 
Figure 2. The correlation between the learners' extraversion personality trait and vocabulary test performance

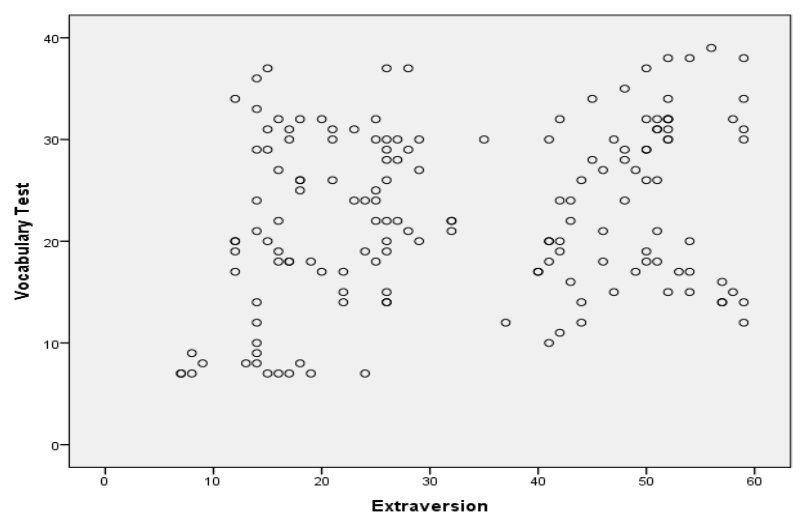

The second research question of the study tried to determine the relationship between the EFL students' personality traits and their grammar test performance. Based on the aims of this research question, a Standard Multiple Regression test was run between the participants' results on the personality inventory and their performance on the grammar test. In the regression analysis, first, the assumption of multicoliniarity had to be checked. The Tolerance and VIF values of the regression model for the grammar test are provided in Table 6 below:

\section{Table 6}

The Collinearity Diagnostics of the Learners' Personality Traits and Grammar Test Performance

\begin{tabular}{lcc}
\hline \multicolumn{1}{c}{ Model } & Tolerance & VIF \\
\hline Neuroticism & .727 & 1.375 \\
Extraversion & .902 & 1.109 \\
Openness to Experience & .875 & 1.143 \\
Agreeableness & .833 & 1.200 \\
Conscientiousness & .748 & 1.337 \\
\hline
\end{tabular}

As Table 6 shows, all of the Tolerance values of the model were more than .10, and all of the VIF values were less than 10. Therefore, the multicollinearity assumption was not violated. Moreover, in order to determine the outliers, the Mahalanobis distance value was checked. The results of residuals statistics for this model are provided in Table 7 below:

Table 7

Regression Model of the Learners' Personality Traits and Grammar Test Performance

\begin{tabular}{llllll}
\hline & Minimum & Maximum & Mean & Std. Deviation & $\mathrm{N}$ \\
\hline Mahal. Distance & 1.127 & 11.145 & 4.968 & 2.261 & 158 \\
Cook's Distance & .000 & .091 & .008 & .014 & 158 \\
\hline
\end{tabular}

As Table 7 shows, the maximum value of the Mahalanobis distance (11.145) was less than 20.52, and the maximum value for the Cook's distance (.091) was less than 1 . Therefore, none of the assumptions was violated. Since all of the assumptions of the Multiple Regression were present, the regression model of the learners' personality traits and grammar test performance was evaluated. Table 8 below provides the summary of this model:

Table 8

The Regression Model Summary of the Learners' Personality Traits and Grammar Test Performance

\begin{tabular}{ccccc}
\hline Model & $\mathrm{R}$ & R Square & Adjusted R Square & Std. Error of the Estimate \\
\hline 1 & .343 & .117 & .088 & 7.178 \\
\hline
\end{tabular}

According to Table 8, this model explains 0.117 (i.e. $R$ Square value) of the variance of the learners' performance on the grammar test. That is, this model explains 11.7 percent (R Square value multiplied by 100 , 
by shifting the decimal point two places to the right) of the variance in the grammar test performance. However, in order to check the statistical significance of the predictive power of the model the results of the ANOVA test of the model had to be checked. The results of this test are provided in Table 9 below:

Table 9

The ANOVA Test of the Regression Model of the Learners' Personality Traits and Grammar Test Performance

\begin{tabular}{lccccc}
\hline \multicolumn{1}{c}{ Model } & Sum of Squares & df & Mean Square & F & Sig. \\
\hline Regression & 1042.187 & 5 & 208.437 & 4.045 & .002 \\
Residual & 7832.174 & 152 & 51.527 & & \\
Total & 8874.361 & 157 & & & \\
\hline
\end{tabular}

As Table 9 shows, the predictive power of the model was not equal to 0 since the p-value of the ANOVA test .002 (marked as Sig.) was less than the level of significance .05. Finally, in order to determine the contribution of each of the independent variables to the prediction of the variance of the grammar test results the Standardized Coefficients had to be checked. These results are provided in Table 10 below:

Table 10

The Coefficients of the Regression Model of the Learners' Personality Traits and Grammar Test Performance

\begin{tabular}{|c|c|c|c|c|c|}
\hline \multirow{2}{*}{ Model } & \multicolumn{2}{|c|}{ Unstandardized Coefficients } & \multirow{2}{*}{$\begin{array}{c}\begin{array}{c}\text { Standardized } \\
\text { Coefficients }\end{array} \\
\text { Beta }\end{array}$} & \multirow{2}{*}{$\mathrm{t}$} & \multirow{2}{*}{ Sig. } \\
\hline & $\mathrm{B}$ & Std. Error & & & \\
\hline (Constant) & 15.675 & 3.664 & & 4.277 & .000 \\
\hline Neuroticism & -.009 & .047 & -.017 & -.195 & .846 \\
\hline Extraversion & .092 & .039 & .190 & 2.368 & .019 \\
\hline Openness to Experience & .180 & .050 & .295 & 3.617 & .000 \\
\hline Agreeableness & .064 & .045 & .117 & 1.402 & .163 \\
\hline Conscientiousness & -.078 & .051 & -.024 & -1.526 & .629 \\
\hline
\end{tabular}

According to Table 10, the largest Beta value is .295 which is for the Openness to Experience variable. Therefore, it can be argued that, this variable makes the strongest unique contribution to explaining the results of the grammar test when the variance explained by all of the other variables in the model is controlled. Moreover, since the p-value for this variable .000 (marked as Sig.) was less than the level of significance .05, it was argued that this variable made a statistically significant unique contribution to the prediction of the grammar test results. Furthermore, based on the results, Extraversion (Beta=.190, Sig=.019) was the second variable that made a significant contribution to the results of this test. The significant contributions of these variables to the explanation of the results of this test are respectively depicted in Figure 3 and Figure 4 below:

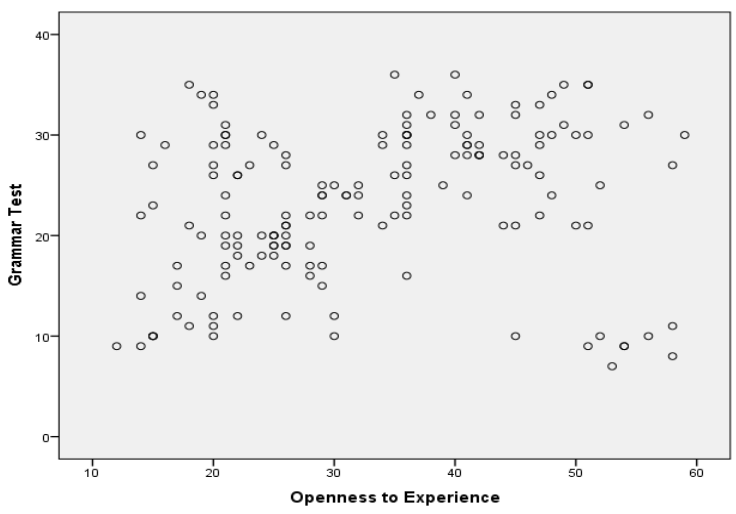

Figure 3. The correlation between the learners' openness to experience personality trait and grammar test performance

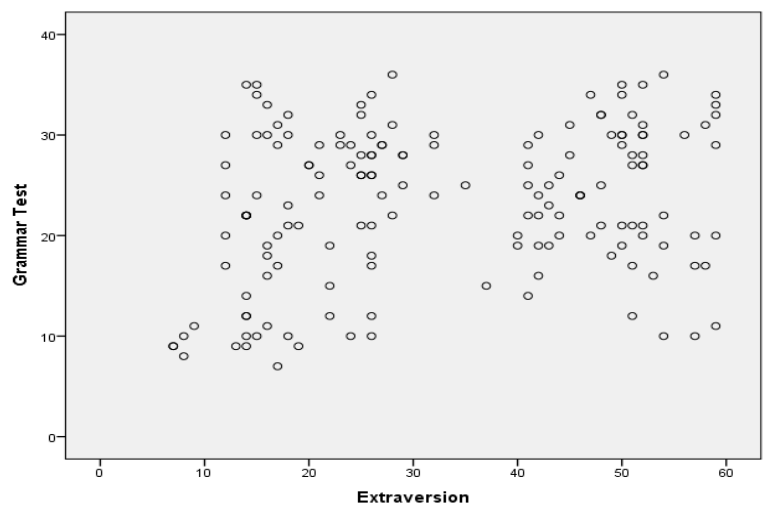

Figure 4. The correlation between the learners' extraversion personality trait and grammar test performance 


\section{Discussions}

The first research question of the study tried to determine the relationship between the learners' personality traits and their performance on the English vocabulary tests. More specifically, it tried to determine how much of the variance in the learners' results on the vocabulary tests can be explained by the learners' personality traits. The results of the data analysis revealed that, the learners' Openness to Experience and Extraversion personality traits were respectively the first and the second variables that made significant contributions to explaining the variance in the results of this test. These results are in line with the results of the studies by Strong (1983), Verhoeven and Vermeer (2002), and Marefat (2006) who have reported significant positive correlations between personality traits and second language test performance.

According to Dewaele and Furnham (2000), the language learners' openness to experience personality trait may help them learn the different aspects of the second language including its vocabulary items. As they explained, the learners with this personality trait: are curious about the meanings of the second language words, focus on the new words in their learning materials, and search the meanings of the new words by the means of various sources. Moreover, as Cooper (2002) argued, the learners with this personality dimension are creative and try to remember the meanings of their new words by the use of self-made learning strategies such as relating the words to specific situational or linguistic contexts. Furthermore, as Eysenck and Chan (1982) argued, the extrovert language learners are very sociable and try to employ their learnt words in different situational contexts with the other language users. According to them, this kind of functional practice helps these students to learn and employ the second language words in a better way in comparison with the other students. Finally, as Milas (2004) stated, the extrovert language learners: are very active, try to focus on the new second language words, and employ the new words in their writing tasks. As he noted, this kind of vocabulary use helps these learners to be able to remember the meanings of the new words.

Based on these issues, it can be argued that, in the present study, the learners with higher degrees of openness to experience and extraversion personality traits had a better performance on the vocabulary test of the study in comparison with the others since they were curious about the meanings of the new second language words and searched their meanings by the help of different kinds of sources. Moreover, these learners were creative and tried to remember the new words by the means of their self-made learning strategies. Finally, these learners were sociable and active and functionally practiced their new words in their writing tasks and oral interactions with their peers or teacher in the language classrooms. Therefore, it can be argued that, the language learners' openness to experience and extraversion personality traits may be systematic sources of test bias and affect their performance on second language vocabulary tests.

The results of the data analysis regarding the grammar test revealed that, the learners' Openness to Experience and Extraversion personality traits were respectively the first and the second variables that made significant contributions to explaining the variance in the results of this test. These results are in line with the results of the studies by Strong (1983), and Verhoeven and Vermeer (2002) who have reported significant positive correlations between personality traits and second language test performance.

According to Cooper (2002), a high degree of openness to experience personality trait may have beneficial effects on the learning of second language forms including the grammar. As he further argued, the learners with this personality trait are more flexible than the other learners in group-based activities and can practice the different kinds of grammatical points with their group members. As he concluded, this kind of practice is very useful for the accurate use of the grammatical structures in the second language. Moreover, as Milas (2004) noted, the learners with this personality trait try to use their learnt grammatical structures in novel ways in various kinds of language learning tasks. According to him, through the use of these structures in various ways, the learners become aware of their errors and try to use the grammatical structures like the native speakers of the target language. 
Furthermore, as Eysenck and Eysenck (1985) stated, the extrovert language learners are likely to learn the formal aspects of the second language better than the others. According to them, these learners are talkative and gregarious and use the different grammatical structures in their interactions with the other language users. As they explained, the use of these structures helps the learners to process them more efficiently and may also help them to employ the structures more accurately based on the feedback that they receive from their interlocutors. Finally, as Eysenck and Chan (1982) stated, the extrovert learners are likely to take more risks regarding the use of the different aspects of the language in comparison with the others. According to them, these learners try to employ the different grammatical structures without any kind of affective inhibition and are able to use these structures more accurately based on the various kinds of formal feedback that they receive from more proficient language users.

Therefore, it can be argued that, in the present study, the learners with higher degrees of openness to experience and extraversion personality traits had a better performance on the grammar test of the study in comparison with the others since they: were more flexible than their peers in the group-based activities, practiced different kinds of grammatical structures, employed their grammatical structures in novel ways, tried to prevent their errors consciously, were able to process the grammatical structures efficiently, were likely to take risks, and employed the grammatical structures of the second language accurately based on the feedback that they received from their peers or teacher in the language classroom. Therefore, it can be concluded that, the language learners' openness to experience and extraversion personality traits may be systematic sources of test bias and affect their performance on the grammar tests of the second language.

Finally, it should be noted that, the results of the present study do not support the results of the studies by Busch (1982), and Dörnyei and Kormos (2000) who did not find any significant correlations between the personality traits and second language test performance.

According to Dörnyei (2005), there are a certain number of factors that lead to the contrasting results of the personality trait studies. First, as he noted, the learners' personality traits may interact with situation-specific variables such as the characteristics of the learning environment. Second, as he explained, the theories of personality are very simplistic and do not account for the ways in which the effect of global personality traits (e.g. openness to experience) on the second language learning are mediated by the learners' personal attributes such as motivation. Third, as he argued, most of the studies investigate the effects of super-traits (e.g. extraversion) on the learning and ignore the investigation of the relationship between the facets of these super-traits and second language achievement. Finally, as he concluded, the methodological differences among the empirical studies such as the differences in the employed measures of second language achievement may lead to different results. Therefore, it can be argued that, the difference between the results of the present study and the mentioned studies may be related to the differences in their: situational variables, theoretical aspects, examined personality facets, and methodological aspects.

\section{Conclusions}

The present study investigated the relationship between the learners' personality traits and their performance on the English vocabulary and grammar tests. The results of the study showed that, the learners' Openness to Experience and Extraversion personality traits had significant positive correlations with their vocabulary and grammar test performance. Based on these results, the EFL teachers are recommended to determine their learners' personality traits by the means of appropriate instruments (e.g. NEO-Five-Factor Inventory). The knowledge of these traits can enable the teachers to recognize the language learners who may have certain problems in second language acquisition. Moreover, they are recommended to make the learners familiar with the characteristics of the learners who are extrovert and open to experience in language acquisition and to encourage them to make efforts in order to develop similar characteristics. Furthermore, the EFL syllabus designers are recommended to include certain sections in the textbooks in which the learners become familiar with the personality aspects of successful language learners and are encouraged to adopt similar language 
Ajideh, P., Yaghoubi-Notash, M., \& Khalili, A.

learning behaviors.

According to Skehan (1989), in the concatenative approach to the study of individual learner differences, the researchers conduct their studies, and then try to develop a theory regarding the relationship between the relevant individual learner difference and test performance based on the results of their studies. As the results of the present study revealed, the concatenative approach may be more informative than a theory-then-research approach in the studies of individual learner differences. Therefore, the language testing specialists are recommended to adopt a research-then-theory (i.e. concatenative) approach in the studies of personality. Moreover, they are recommended to redefine the construct of second language ability in light of the results of the individual learner difference studies including the present study.

However, there is a need for various empirical studies of individual learner differences in different learning contexts and educational settings in order to make wide-reaching conclusions about the role of these differences as sources of test bias. For instance, the future studies should involve language learners from different mother tongues, and language proficiency levels in order to provide more information regarding the non-linear and variable role of the individual learner differences in the explanation of the variance in second language tests. In addition, the future studies should investigate the individual learner differences (e.g. cultural background, background knowledge, \& ethnicity) which were not included in the present study.

\section{References}

Bachman, L. F. (1990). Fundamental considerations in language testing. Oxford: Oxford University Press.

Busch, D. (1982). Introversion-extroversion and the EFL proficiency of Japanese students. Language Learning,

32, 109-132. https://doi.org/10.1111/j.1467-1770.1982.tb00521.x

Carroll, J. B., \& Sapon, S. (1959). The modern languages aptitude test. San Antonio: Psychological Corporation. Cooper, C. (2002). Individual differences ( $2^{\text {nd }}$ Ed.). London: Arnold.

Costa, P. T., \& McCrae, R. R. (1992). NEO-PI-R: Professional manual. Odessa: Psychological Assessment Resources.

Creswell, J. W. (2011). Educational research: Planning, conducting and evaluating quantitative and qualitative research $\left(4^{\text {th }}\right.$ Ed.). New York: Pearson Education.

De Raad, B. (2000). Differential psychology. In A. E. Kazdin (Ed.), Encyclopedia of psychology (pp. 41-44). Oxford: American Psychological Association and Oxford University Press. https://doi.org/10.1037/10518-012

Dewaele, J. M., \& Furnham, A. (2000). Personality and speech production: A pilot study of second language learners. Personality and Individual Differences, 28, 355-365. https://doi.org/10.1016/S0191-8869(99)00106-3

Dörnyei, Z. (2005). The psychology of the language learner: Individual differences in second language acquisition. Mahwah: Lawrence Erlbaum.

Dörnyei, Z., \& Kormos, J. (2000). The role of individual and social variables in oral task performance. Language Teaching Research, 4, 275-300. https://doi.org/10.1191/136216800125096

Ehrman, M. E., \& Oxford, R. L. (1995). Cognition plus: Correlates of language learning success. Modern Language Journal, 79(1), 67-89. https://doi.org/10.1111/j.1540-4781.1995.tb05417.x

Ellis, R. (2008). The study of second language acquisition ( $2^{\text {nd }}$ Ed.). Oxford: Oxford University Press.

Eysenck, H. J., \& Eysenck, M. W. (1985). Personality and individual differences. New York: Plenum.

Eysenck, S. B. G., \& Chan, J. (1982). A comparative study of personality in adults and children: Hong Kong vs. England. Personality and Individual Differences, 3, 153-160. https://doi.org/10.1007/978-1-4613-2413-3

Farhady, H. (1982). Measures of language proficiency from the learner's perspective. TESOL Quarterly, 16(1), 43-59. https://doi.org/10.2307/3586562

Goldberg, L. R. (1992). The development of markers for the big-five factor structure. Psychological Assessment, 4(1), 26-42. https://doi.org/10.1037/1040-3590.4.1.26 
Harris, D. P. (1969). Testing English as a second language. New York: McGraw-Hill.

Horwitz, E. K. (2000). Teachers and students, students and teachers: An ever-evolving partnership. The Modern Language Journal, 84, 523-535. https://doi.org/10.1111/0026-7902.00085

Lee, L., \& Gundersen, E. (2011). Intermediate select readings. Oxford: Oxford University Press.

Lesly, T., Hansen, Ch., \& Zukowski, J. (2003). New interchange passages placement and evaluation package. New York: Cambridge University Press.

Mall-Amiri, B., \& Nakhaie, N. (2013). Comparing the performance of extrovert and introvert intermediate female EFL learners on listening and reading tasks. International Journal of Language Learning and Applied Linguistics World, 3(3), 11-29.

Marefat, F. (2006). Student writing, personality type of the student and the rater: An interrelationship? The Reading Matrix, 6(2), 166-124.

McCrae, R. R., \& Costa, P. T. (2003). Personality in adulthood: A five-factor theory perspective ( $2^{\text {nd }}$ Ed.). New York: Guilford Press. https://doi.org/10.4324/9780203428412

Milas, G. (2004). Personality and social attitudes. Jastrebarsko: Naklada Slap.

Myers, I. B., \& Briggs, K. (1976). The Myers-Briggs type indicator. Paolo Alto: Consulting Psychologists Press.

Pallant, J. (2007). SPSS survival manual: A step by step guide to data analysis using SPSS for windows (3 ${ }^{\mathrm{rd}} \mathrm{Ed}$.). Berkshire: McGraw-Hill House.

Pervin, L. A., \& John, O. P. (2001). Personality: Theory and research ( $8^{\text {th }}$ Ed.). New York: John Wiley \& Sons.

Richards, J. C., \& Schmidt, R. (2010). Longman dictionary of language teaching and applied linguistics $\left(4^{\text {th }}\right.$ Ed.). Edinburg: Pearson Education.

Segalowitz, N. (1997). Individual differences in second language acquisition. In A. de Groot, M. Kroll, \& J. Kroll (Eds.), Tutorials in bilingualism: Psycholinguistic perspectives (pp. 78-93). Mahvah: Lawrence Erlbaum.

Skehan, P. (1989). Individual differences in second language learning. London: Edward Arnold.

Strong, M. (1983). Social styles and second language acquisition of Spanish-speaking kindergarteners. TESOL Quarterly, 17, 241-258. https://doi.org/10.2307/3586652

Verhoeven, L., \& Vermeer, A. (2002). Communicative competence and personality dimensions in first and second language learners. Applied Psycholinguistics, 23, 361-374. https://doi.org/10.1017/S014271640200303X 
Ajideh, P., Yaghoubi-Notash, M., \& Khalili, A. 